OP64

\title{
EVIDENCE-BASED RESEARCH AND APPLICATIONS OF A THERAPEUTIC LIGHTING SYSTEM ON CIRCADIAN RHYTHM AND MOOD REGULATION FOR CHINESE PATIENTS
}

\author{
Luoxi Hao et al.
}

DOI 10.25039/x46.2019.OP64

from

CIE x046:2019

\author{
Proceedings \\ of the \\ 29th CIE SESSION
}

Washington D.C., USA, June 14 - 22, 2019

(DOI $10.25039 / \times 46.2019)$

The paper has been presented at the 29th CIE Session, Washington D.C., USA, June 14-22, 2019. It has not been peer-reviewed by CIE.

(C) CIE 2019

All rights reserved. Unless otherwise specified, no part of this publication may be reproduced or utilized in any form or by any means, electronic or mechanical, including photocopying and microfilm, without permission in writing from CIE Central Bureau at the address below. Any mention of organizations or products does not imply endorsement by the CIE.

This paper is made available open access for individual use. However, in all other cases all rights are reserved unless explicit permission is sought from and given by the CIE.

CIE Central Bureau

Babenbergerstrasse 9

A-1010 Vienna

Austria

Tel.: +4317143187

e-mail: ciecb@cie.co.at

www.cie.co.at 


\title{
EVIDENCE-BASED RESEARCH AND APPLICATIONS OF A THERAPEUTIC LIGHTING SYSTEM ON CIRCADIAN RHYTHM AND MOOD REGULATION FOR CHINESE PATIENTS
}

\author{
Hao,L.X. ${ }^{1,2}$, Cao, Y.X. ${ }^{1,2}$ \\ ${ }^{1}$ College of Architecture and Urban Planning, Tongji University; Shanghai, CHINA, \\ ${ }^{2}$ Key Laboratory of Ecology and Energy Saving Study of Dense Habitat (Tongji \\ University),Ministry of Education, CHINA \\ haoluoxi@tongji.edu.cn
}

DOI $10.25039 / \times 46.2019 .0 P 64$

\begin{abstract}
The study aims to explore the strategies of indoor lighting suitable for patients, promote the patients' circadian rhythm repair and emotional regulation by effectively utilizing the active health intervention effect of light environment, improve the outcome of disease treatment and enhance the patients' quality of life. Based on a series of evidence-based research, the lighting parameters combination that can improve the rhythm and mood is proposed in the problemoriented the study. The therapeutic lighting system composed by circadian lighting module, mood lighting module and intelligent control system is designed. The demonstration application of the system and the evaluation after using are completed in the hospital and old-age care institutions. Clinical application feedback shows that the system significantly improves patients' sleep quality and treatment compliance, and has good therapeutic effect.
\end{abstract}

Keywords: Therapeutic Lighting, Circadian Rhythm Repair, Emotional Regulation

\section{Introduction}

Disease symptoms, side effects of treatment, and changes in daily behaviours and habits tend to cause abnormal biological rhythm and emotional fluctuation in patients, which seriously affect the treatment and prognosis of the disease (increase the risk of surgery, cause exacerbation or recurrence, or complications(Araújo 2012),(Pinto 2016)). A lot of seizures and drug absorption, metabolism, and toxicity present day-night oscillations. In order to obtain the better therapeutic effect and reduce side effects, it is important to match the timing of drug delivery, radiation therapy, surgery, and organ transplantation with patients' circadian rhythms, especially for diseases such as cancer, cardiovascular disease, and inflammation(Sajan 2009)(Kondratov 2014)(Ballesta 2017). A stable emotional state is also helpful to improve patients' treatment compliance and avoid adverse events(McCormic 2013). Therefore, circadian rhythm and mood regulation is indispensable for patients to recover and improve the quality of life.

Since intrinsically photosensitive retinal ganglion cells (ipRGCs) were discovered 20 years ago, the health effect of light stimulation on human emotion and rhythm through visual and nonvisual neural pathways has been extensively concerned. An increasing number of studies have confirmed that specific light can improve the symptoms of various diseases such as seasonal affective disorder, non-seasonal affective disorder, sleep disorder and related dementia(Lavoie 2009)(. From the perspectives of the physiological mechanism of action and the contrast experiment research with human samples, many researches explore the response of circadian rhythm and mood to white light illumination and colour light (Plitnick 2010), obtain some correlation rule as well as the lighting indicators that can promote restoration of the circadian rhythms and regulate mood.

Individual patients and various diseases are highly specific. Moreover, race, gender, age, course of disease, genetic background and the treatment received by patients have an impact on the effect of light stimulation(Knez 2000). Besides, attention also should be paid to social medical systems of different countries. Therefore, the problem-oriented evidence-based research method was adopted in the study, As for the research technical route, first of all,a longitudinal follow-up study was conducted to understand the circadian rhythm and emotional 
problems that the patients encountered in the whole process of treatment, rehabilitation and prognosis. The therapeutic lighting objective was determined. The response of circadian rhythm and mood to different lighting conditions was verified through evidence-based research with the combination of subjective scale evaluation and objective physiological data measurement. Additionally, the "therapeutic lighting system of improving the circadian rhythm and mood" composed by circadian lighting module, mood lighting module and control system was custom designed. Multi-scenario illumination environment control strategy was developed. Finally, the system was demonstrated in hospitals and nursing institutions, and the parameters of the system were optimized according to the feedback results. With the ultimate goals of proposing a lighting solution for health benefit maximization and achieving its floor application, this study intends to facilitate the rehabilitation of patients and improve their quality of life by taking indoor lighting environment as a direct, effective and safe healing measure without side effects.

\section{Evidence-based research and design}

The concept of "evidence-based" first appeared in the medical field. It is a process of systematically collecting evidence, raising questions, testing hypotheses and seeking the best solution through observation and experiments. It is also an appropriate means to study complex problems such as the correlation between patients' circadian rhythm and mood and illumination factors. The evidence-based experiment in the study included two parts: the basic research on the influence of light environment on Chinese people's circadian rhythm and emotional intervention, and the evidence-based design study on the light environment in the inpatient wards. The results provided the basis for the design parameters selection of the illumination system.

\subsection{Experimental study on the effects of different illumination parameters on circadian rhythms and mood}

At present, a large number of studies about the influence of light on human circadian rhythms and mood have basically determined that light intensity, light duration, light time, spectral distribution, previous light exposure and the colour, brightness and dynamic change of coloured light are the key elements affecting circadian rhythm and mood state(Küller 2006)(Duffy 2009)(Bedrosian 2017). Due to the differences in experimental conditions and objects, however, no unified experimental results have been achieved. Meanwhile, the preliminary conclusions may differ from those with the research object of Asian ones. Therefore, two experiments namely, "Experimental study on the effect of light colour with different wavelengths on human melatonin" and "Experimental study on the effect of continuous spectrum (white light LED) on melatonin" were conducted in the study so as to explore the impact of different light conditions on the circadian rhythm of Chinese patients. In the experiment, based on the collected saliva samples, the concentration of melatonin was analyzed and the human circadian rhythm was evaluated. Besides, sleep log and smart bracelet sleep monitoring data were used as the auxiliary judgment basis. "Experimental study on the effect of white light illumination on mood" and "Experimental study on the effect of colour light on mood" were conducted to discuss the impact of white light environment and colour light environment on human emotion. The "anxiety self-rating scale" and "depression self-rating scale" were used as subjective evaluation means to distinguish the emotional state of the subjects. The semantic differential scale was applied to evaluate the subjective feelings of the subjects. Based on EEG data, the percentage values of $\theta, \alpha$ and $\beta$ wave energy of $\mathrm{O} 1$ and $\mathrm{O} 2$ channels were analyzed to evaluate the emotional change.To eliminate the interference of disease conditions, environment and individual psychological factors on the experimental results, healthy people with a high degree of cooperation, good physical condition and stable mood were selected as subjects in these experiments. 
Table 1 - Contents and conclusions of the basic research on the influence of light environment on circadian rhythm and mood

\begin{tabular}{|c|c|c|c|c|}
\hline Researches & $\begin{array}{l}\text { Subject } \\
\text { selection }\end{array}$ & Research parameters & Contents & Result analysis \\
\hline $\begin{array}{l}\text { Experimental } \\
\text { study on the } \\
\text { effect of light } \\
\text { color with } \\
\text { different } \\
\text { wavelengths } \\
\text { on human } \\
\text { melatonin" }\end{array}$ & $\begin{array}{l}\text { Quantity: } 19 \\
\text { Age: } 24-28 \\
7 \text { female } \\
12 \text { male }\end{array}$ & $\begin{array}{l}\text { Wavelengths: } \\
\text { 460nm 480nm 532nm } \\
625 \mathrm{~nm}\end{array}$ & $\begin{array}{l}\text { Inhibition } \\
\text { rate of } \\
\text { melatonin } \\
\text { Circadian } \\
\text { phase }\end{array}$ & $\begin{array}{l}480 \mathrm{~nm} \text {, } \\
\text { Inhibition rate: } 70.46 \% \\
\text { Phase delay: } 1.75 \mathrm{~h} \\
460 \mathrm{~nm} \\
\text { Inhibition rate: } 61.94 \% \\
\text { Phase delay: } 1.642 \mathrm{~h} \\
\text { Short wavelength blue } \\
\text { light has obvious effects } \\
\text { on melatonin inhibition } \\
\text { and phase delay. }\end{array}$ \\
\hline $\begin{array}{l}\text { Experimental } \\
\text { study on the } \\
\text { effect of } \\
\text { continuous } \\
\text { spectrum } \\
\text { (white light } \\
\text { LED) on } \\
\text { melatonin }\end{array}$ & $\begin{array}{l}\text { Quantity: } 20 \\
\text { Age: } 19-26 \\
8 \text { female } \\
12 \text { male }\end{array}$ & $\begin{array}{l}\text { Illuminance: } \\
\text { 2000Ix 500Ix 50Ix } \\
\text { CCT: } \\
2700 \mathrm{~K} 4500 \mathrm{~K} 9000 \mathrm{~K}\end{array}$ & $\begin{array}{l}\text { Inhibition } \\
\text { rate of } \\
\text { melatonin } \\
\text { Circadian } \\
\text { phase }\end{array}$ & $\begin{array}{l}\text { Under the same } \\
\text { illumination intensity } \\
(2000 \mathrm{x}) \text {, the white light } \\
\text { of } 4500 \mathrm{~K} \text { and } 9000 \mathrm{~K} \\
\text { had obvious effects on } \\
\text { melatonin inhibition and } \\
\text { phase delay. } \\
\text { At the same color } \\
\text { temperature }(9000 \mathrm{~K}) \text {, } \\
\text { the white light of } \\
2000 \mathrm{Lx} \text { and } 500 \mathrm{Lx} \text { had } \\
\text { significant rhythm } \\
\text { impact. }\end{array}$ \\
\hline $\begin{array}{l}\text { Experimental } \\
\text { study on the } \\
\text { effect of } \\
\text { white light } \\
\text { illumination } \\
\text { on mood }\end{array}$ & $\begin{array}{l}\text { Quantity: } 20 \\
\text { Age: } 20-30 \\
10 \text { female } \\
10 \text { male }\end{array}$ & $\begin{array}{l}\text { Illuminance: } \\
\text { 100Ix 200Ix 400Ix } \\
\text { CCT: } \\
\text { 3000K 4000K 5700K } \\
\text { Direct illumination } \\
\text { Contribution rate: } \\
100 \% 70 \% 50 \% \\
30 \% 0 \%\end{array}$ & $\begin{array}{l}\text { Emotional } \\
\text { state } \\
\text { Subjective } \\
\text { satisfaction } \\
\text { EEG } \\
\text { signal }\end{array}$ & $\begin{array}{l}\text { Within the threshold of } \\
400 \mathrm{x} \text {. The higher the } \\
\text { illumination, the higher } \\
\text { the satisfaction of the } \\
\text { subjects. } \\
3000 \mathrm{~K} \text { and Direct and } \\
\text { indirect lighting were } \\
\text { preferred } \\
4001 \mathrm{x}, 3000 \mathrm{~K} \text { with } 30 \% \\
\text { direct illumination } \\
\text { contribution rate were } \\
\text { the lighting condition } \\
\text { that relatively met the } \\
\text { emotional preference of } \\
\text { most subjects. }\end{array}$ \\
\hline $\begin{array}{l}\text { Experimental } \\
\text { study on the } \\
\text { effect of } \\
\text { colour light } \\
\text { on mood }\end{array}$ & $\begin{array}{l}\text { Quantity: } 20 \\
\text { Age: } 20-30 \\
8 \text { female } \\
12 \text { male }\end{array}$ & $\begin{array}{l}\text { Light color: } \\
\text { Yellow } \\
\text { (RGB } 20724698) \\
\text { Light yellow } \\
(246,18298) \\
\text { Blue }(98 \quad 246231) \\
\text { Rose red } \\
\text { (239 } 98246) \\
\text { Powder (175 98 246) } \\
\text { Light Blue } \\
\text { (26 77, 255) } \\
\text { White light. }\end{array}$ & $\begin{array}{l}\text { Emotional } \\
\text { state } \\
\text { Subjective } \\
\text { satisfaction } \\
\text { EEG } \\
\text { signal }\end{array}$ & $\begin{array}{l}\text { Color light can affect } \\
\text { patients'mood. } \\
\text { The warm yellow, light } \\
\text { yellow and light blue } \\
\text { close to natural light } \\
\text { were preferred. } \\
\text { The bright and eye- } \\
\text { catching colours (rose } \\
\text { red and blue) had a } \\
\text { negative effect on } \\
\text { subjects' emotions } \\
\text { should be used carefully } \\
\text { in emotional lighting. }\end{array}$ \\
\hline
\end{tabular}




\subsection{Evidence-based design study}

Circadian rhythm disorders and negative emotions such as depression and anxiety are common problems among patients with severe cardiac disease and Alzheimer's disease. In order to apply the "therapeutic illumination system" to the rehabilitation environment of these two types of patients, and provide an effective therapeutic regimen of illumination, an evidence-based design study was conducted. "Therapeutic lighting system" was installed in the experimental space, and various experimental scenes were formed by adjusting system parameters. The design parameters of each illumination mode were determined according to the patients' feedback to each illumination scene.

\subsubsection{Evidence-based design of CICU light environment}

The full-scale mock-up of a typical CICU single ward was established. ECG monitor, infusion rack, medical partition curtain and simple equipment belt were equipped. And the subjects who had been hospitalized in the Department of Cardiology and clinical care in the Department of Cardiology were recruited. to The scene of hospitalization in the Department of Cardiology was restored as far as possible, so as to improve the reliability of the experimental results The "therapeutic illumination system" is installed on the ceiling just above the tail of the bed to provide direct illumination. Linear headlamps provide indirect lighting. During the experiment, the shade curtain was used to remove the effect of self-light. In the experiment, male and female patients gave subjective satisfaction scores for the preset white lighting environment provided by the circadian lighting module and the lighting interface design elements of the emotional module through the semantic difference scale. The results show that for patient recuperation, $200 \mathrm{~lx}$ illumination, $3000 \mathrm{~K}$ colour temperature and over $70 \%$ indirect illumination were the ideal white lighting environment. Medical staff had more demands for visual operation, so they preferred the parameter combination of $200 \mathrm{~lx}$ illumination, $3000 \mathrm{~K}$ colour temperature, $70 \%$ indirect illumination and $30 \%$ direct illumination. Among the dominant light colors in the illumination media interface set in the experiment, male patients had the highest satisfaction score for light cyan $(x=0.1789, y=0.2073)$, being the only dominant light colours has higher satisfaction score than the white light reference lighting scene. Female patients had the highest satisfaction score for Cyan $(x=0.1494, y=0.2039)$, being the only dominant light colour higher than the white light baseline scene. Despite the changes in the surface brightness of the illumination media interface, there were no significant differences in the perception and evaluation of the environment between male and female subjects. Male and female subjects gave the highest satisfaction score for 20 s of the change cycle and the lowest score for $6 \mathrm{~s}$ of change cycle in the three change cycles of $6 \mathrm{~s}, 10 \mathrm{~s}$ and $20 \mathrm{~s}$. Light environment could improve patients' satisfaction and regulate emotions, but the selection of parameters, especially the colour and dynamic setting of light media interface should be very serious.
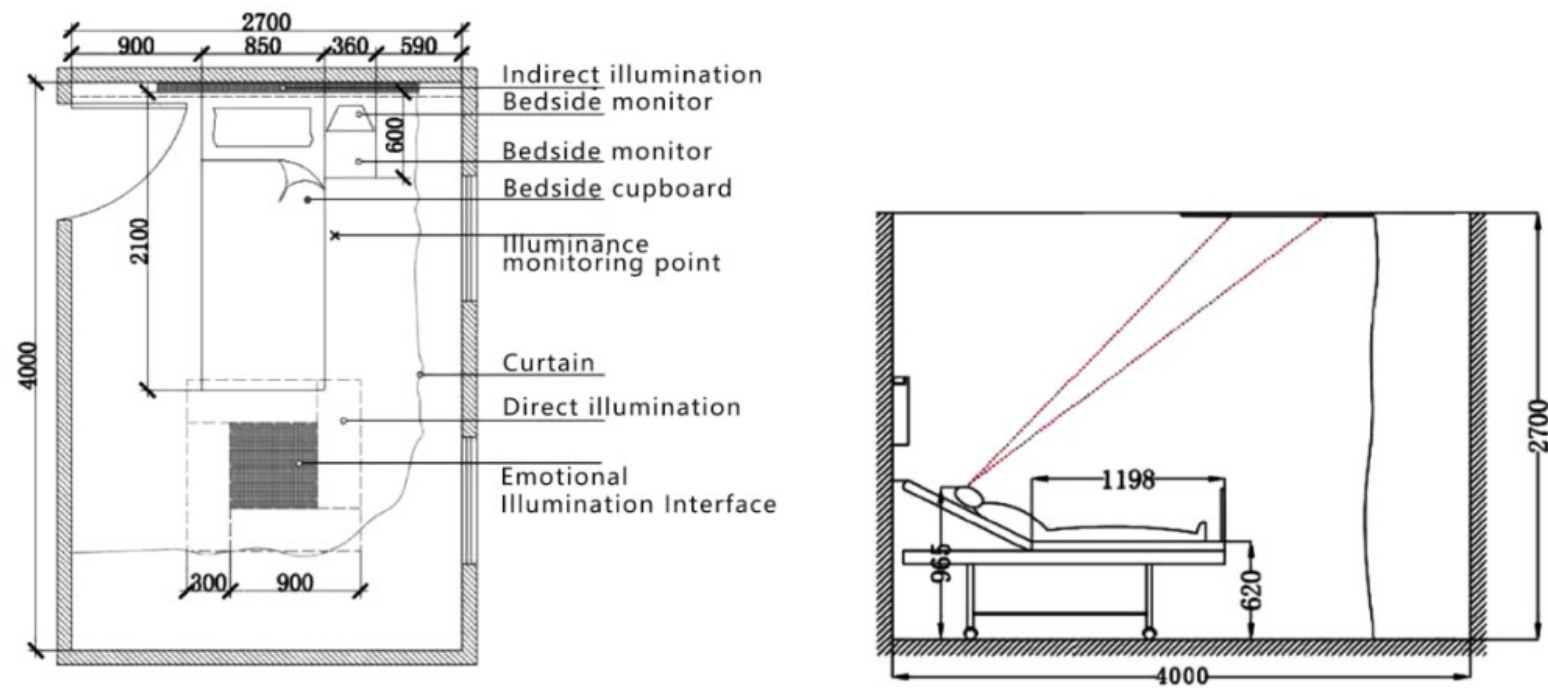

Figure 1 - The layout of the CICU simulated ward 


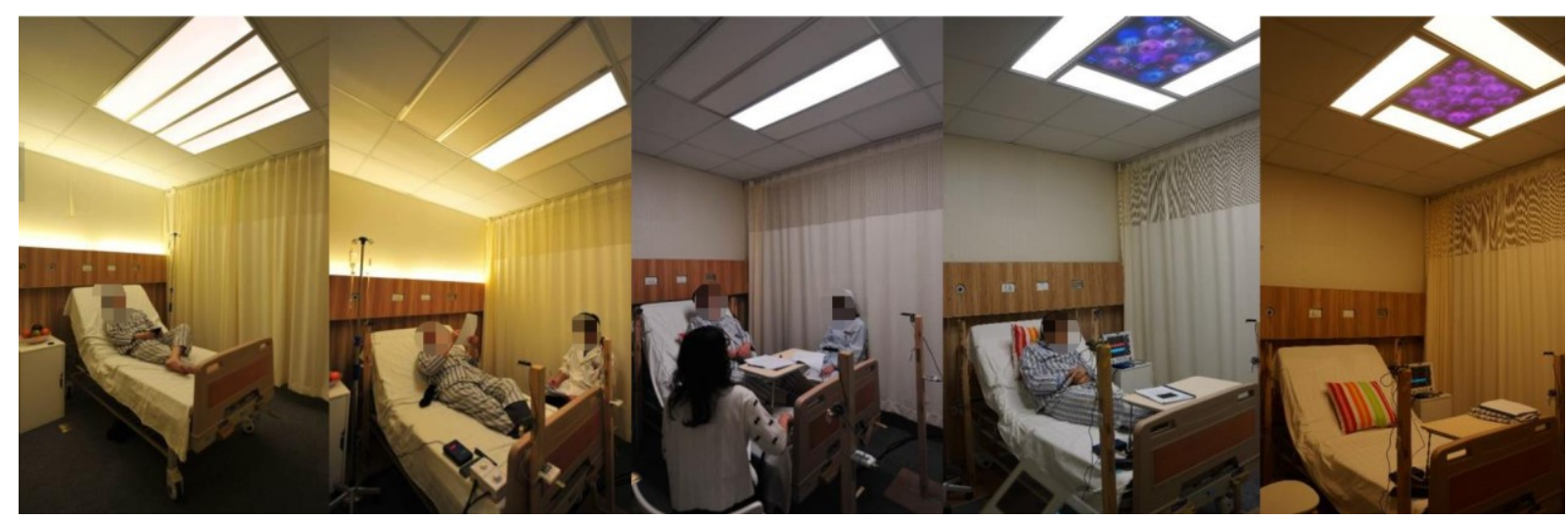

Figure 2 - Research scenario of evidence-based design for CICU light environment

\subsubsection{Evidence-based design study of light environment in the care ward for patients with Alzheimer's disease}

Patients with Alzheimer's diseases are more specific and they have limited mobility and cognition. so it is difficult to ask patients to complete the experiment by moving to the laboratory. This study presented lighting scenes with the help of virtual reality (VR) technology and constructed a real-time interactive and immersive simulation environment experience for them. The experiment was completed in the Mentally Disabled Elderly Care Center of Shanghai Third Welfare Home. A 6-bed standard nursing unit was used as the prototype to build a virtual scene. The lighting condition of the virtual experiment scene was simulated through Dialux Evo to ensure the consistency between the luminosity data and reality. The experiment took the lighting mode (direct overhead light, bedside light, indirect wall light and natural light simulation interface as the variable. Based on the "behavioral-lighting pattern matching" and evaluation and analysis of "semantic difference scale", the preference for illumination mode and subjective feeling of illumination scenes of the elderly in different activities were analyzed and the lighting modes suitable for the behaviour of the senile with dementia, such as waking up in the morning, daily activities, eating and taking a lunch break, were proposed.

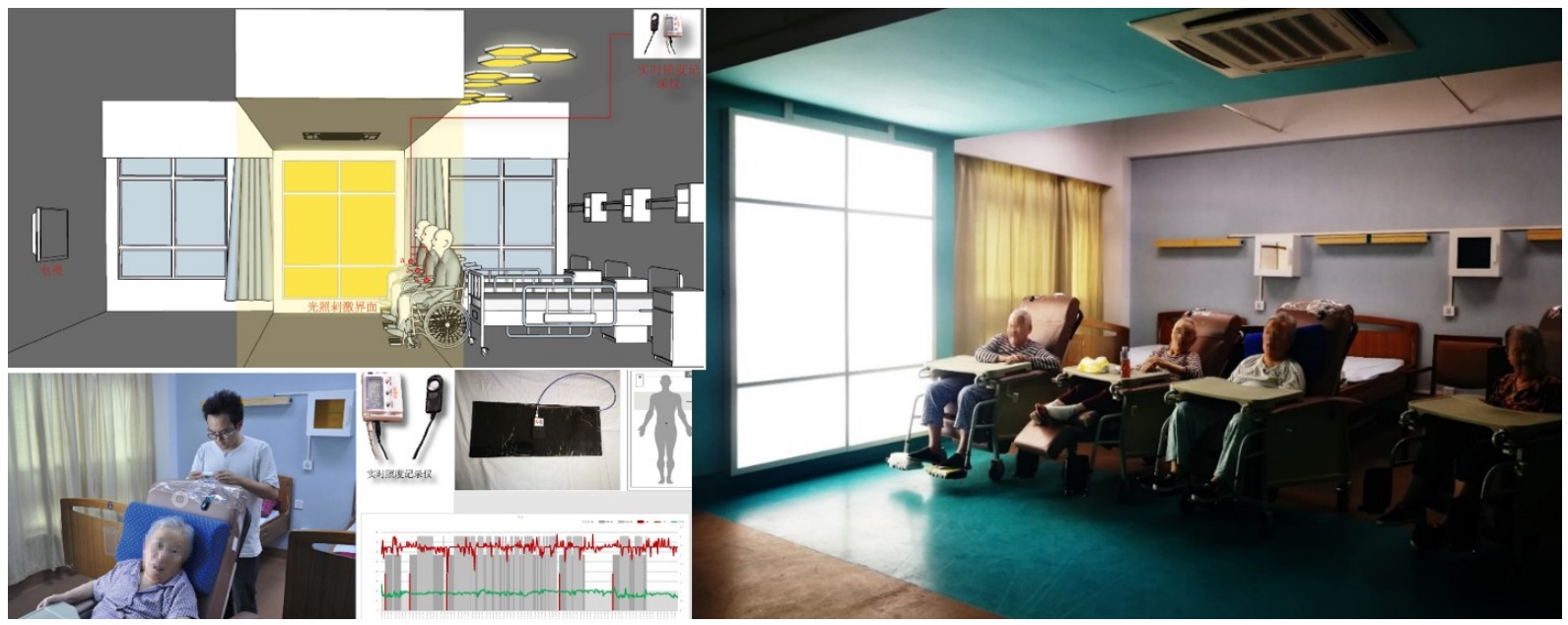

Figure 3 - Research scenario of evidence-based design for alzheimer's disease care ward

\section{A therapeutic lighting system on circadian rhythm and mood regulation}

The "therapeutic lighting system" was composed by circadian lighting module, mood lighting module, and control system. The standard form was a combination of a central $600 \mathrm{~mm} \times 600 \mathrm{~mm}$ illumination media interface surrounded by 4 pieces as rhythm lighting $300 \mathrm{~mm} \times 900 \mathrm{~mm}$ LED panel light. The size and form of each module could be customized according to the application object and space design. 
The circadian lighting module provided indoor functional lighting to meet the needs of clinical treatment and human activities, and therapeutic lighting with rhythm repair effect. The rhythm lighting module, which colour temperature and illumination were continuously adjustable, could dynamically simulate the change of natural light, and also provide high-intensity white light and blue-rich white light lighting mode as required for the improvement of the symptoms of patients with sleep disorders and mood disorders including unseasonal depression.

The emotional lighting module was a lighting media interface with a special dielectric layer. The optical dielectric layer, as an important imaging factor, included LED base layer, optical dielectric layer and image bearing layer.which made the low-pixel LED luminescent screen present clear artistic graphics and produce unique artistic effects. This technology has obtained the national invention patent. The interface display image and colour could be customized according to the target application crowd and space. The design and simulation of the images were also completed under the guidance of the evidence-based design concept. As for the setting of the image complexity, density, size and other factors, the patients' emotional experience and visual experience from the perspectives of lying down, semi-lying down and sitting down were comprehensively considered.

The built-in programmable controller of "therapeutic lighting system" could precisely control the parameters of rhythm illumination and emotional illumination module, meet the requirements of multi-mode illumination, and achieve 24-hour dynamic therapeutic lighting for individual patients.

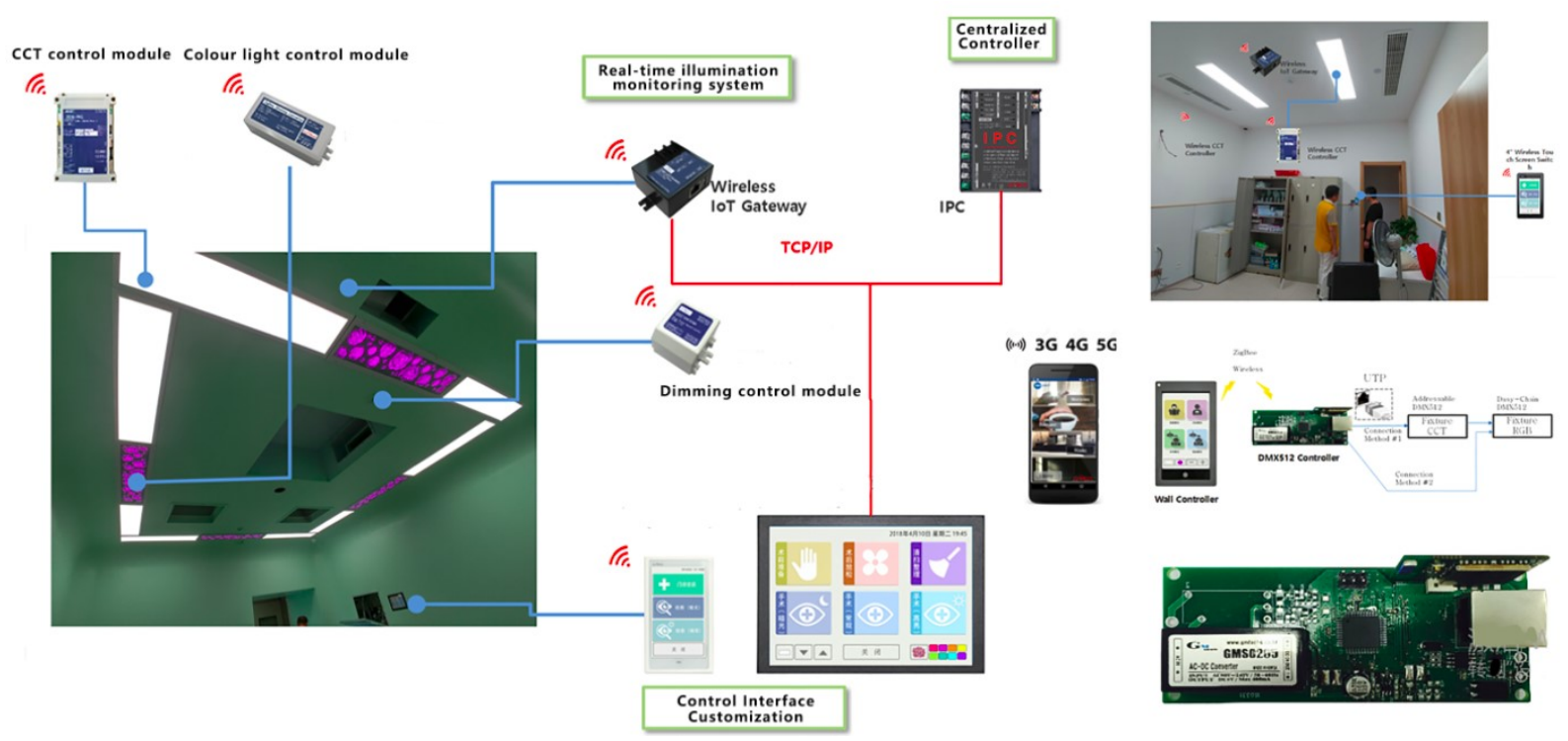

Figure 4 - Multi-scene lighting control system schematic

\section{Application Demonstration and Post-occupancy evaluation}

After the emotional illumination interface of "therapeutic lighting system" was installed in the Catheter Operating Room of Department of Cardiology of Shanghai 10th People's Hospital and was demonstrated. A postoperative evaluation study was conducted by the application institution, and 200 cases of patients (108 male cases $64.69+10.89 \mathrm{y} / 92$ female cases $68.39+9.19 y)$ undergoing cardiac interventional surgery were selected and divided into experimental group and control group according to the time period of the program, with 100 patients in each group. The traditional nursing measures were used in the control group, and the "emotional lighting interface" was used as emotional nursing methods in the experimental group. The changes of vital signs, the incidence of vasospasm, anxiety and conscious pain during interventional surgery and the occurrence of complications of vasospasm, anxiety and conscious pain during the operation were observed and evaluated. The results showed that the emotional lighting system had the effect of colour evocation induction on the patients, and diverted the patients' attention to some extent, and played an auxiliary role in avoiding the patients' vagus. At the same time, cardiac intervention could alleviate anxiety, reduce the 
incidence of vasospasm, cut down pains, and effectively improve the compliance of patients undergoing interventional surgery, had a positive effect on the improvement of mood.

Table 2 - Comparison of vital signs between the experimental group and control group

\begin{tabular}{|c|c|c|c|c|c|c|c|c|}
\hline & \multicolumn{2}{|c|}{$\begin{array}{l}\text { Heart rate } \\
\text { (times/min) }\end{array}$} & \multicolumn{2}{|c|}{$\begin{array}{l}\text { Systolic pressure } \\
{[\mathrm{mmHg}]}\end{array}$} & \multicolumn{2}{|c|}{$\begin{array}{c}\text { Diastolic pressure } \\
{[\mathrm{mmHg}]}\end{array}$} & \multicolumn{2}{|c|}{$\begin{array}{l}\text { Breathing } \\
\text { (times/min) }\end{array}$} \\
\hline & $\begin{array}{c}\text { Pre- } \\
\text { operative }\end{array}$ & $\begin{array}{c}\text { Post- } \\
\text { operative }\end{array}$ & $\begin{array}{c}\text { Pre- } \\
\text { operative }\end{array}$ & $\begin{array}{c}\text { Post- } \\
\text { operative }\end{array}$ & $\begin{array}{c}\text { Pre- } \\
\text { operative }\end{array}$ & $\begin{array}{c}\text { Post- } \\
\text { operative }\end{array}$ & $\begin{array}{c}\text { Pre- } \\
\text { operative }\end{array}$ & $\begin{array}{c}\text { Post- } \\
\text { operative }\end{array}$ \\
\hline $\begin{array}{l}\text { Control } \\
\text { group } \\
(n=100)\end{array}$ & $90 \pm 13.5$ & $88 \pm 15.7$ & $130 \pm 18$ & $128 \pm 17$ & $86 \pm 11$ & $86 \pm 10$ & $20 \pm 2.0$ & $18 \pm 2.1$ \\
\hline $\begin{array}{l}\text { Experimen } \\
\text { tal group } \\
\quad(n=100)\end{array}$ & $\begin{array}{c}89.8 \pm 1 \\
8\end{array}$ & $\begin{array}{c}81.7 \pm 1 \\
8\end{array}$ & $131 \pm 20$ & $125 \pm 18$ & $85 \pm 9$ & $80 \pm 8$ & $21 \pm 1.7$ & $18 \pm 1.8$ \\
\hline P-values & \multicolumn{2}{|c|}{$<0.05$} & \multicolumn{2}{|c|}{$<0.05$} & \multicolumn{2}{|c|}{$<0.05$} & \multicolumn{2}{|c|}{$<0.05$} \\
\hline
\end{tabular}

Table 3 - Comparison of complication rate between the experimental group and control group

\begin{tabular}{|c|c|c|c|}
\hline & $\begin{array}{c}\text { Vasospasm } \\
{[\mathrm{n}(\%)]}\end{array}$ & $\begin{array}{c}\text { Anxiety complain } \\
{[\mathrm{n}(\%)]}\end{array}$ & $\begin{array}{c}\text { Conscious pain } \\
{[\mathrm{n}(\%)]}\end{array}$ \\
\hline $\begin{array}{c}\text { Experiment } \\
\text { group }(\mathrm{n}=100)\end{array}$ & $4(4)$ & $10(10)$ & $3(3)$ \\
\hline $\begin{array}{c}\text { Control group } \\
(\mathrm{n}=100)\end{array}$ & $15(15)$ & $22(22)$ & $12(12)$ \\
\hline P value & $<0.05$ & $<0.05$ & $<0.05$ \\
\hline
\end{tabular}
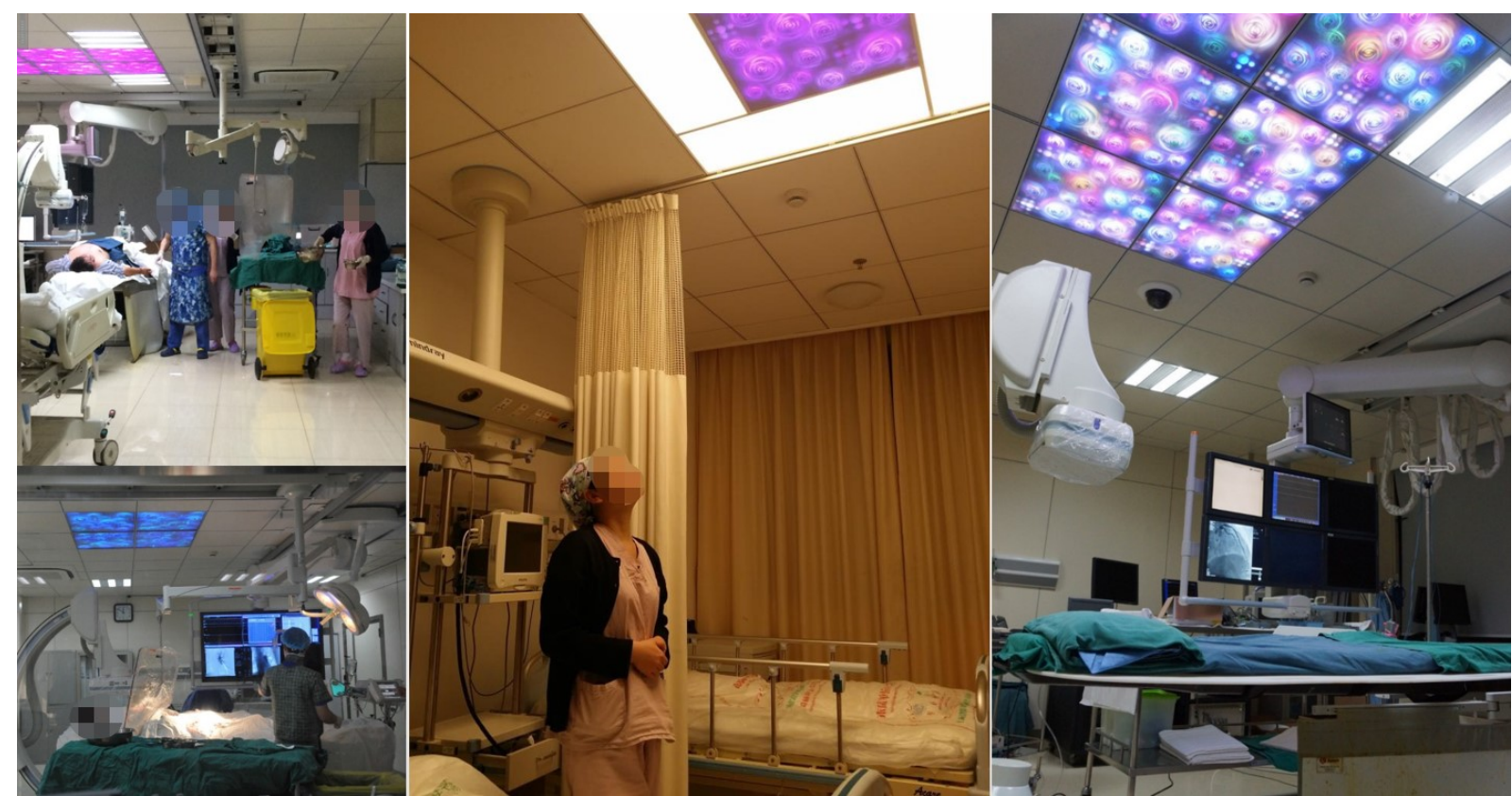

Figure 5 - Demonstration application of therapeutic illumination system in Shanghai Tenth People's Hospital

4 elderly people were arranged to receive $1000 \mathrm{Lx}, 5000 \mathrm{~K}$ and $1000 \mathrm{Lx}, 9000 \mathrm{~K}$ bright white light stimulation using the rhythm illumination module at 9:30 10:30 PM and 1:30 2:30PM daily after the installation of the "therapeutic illumination system" in the Elderly Care Center of Shanghai 
Third Welfare Home for The Mentally Disabled. In the study, sleep mattresses were used to monitor the sleep status of the elderly. The information of sleep parameters, leaving bed, going to bed, body movement and other information of 2 elderly people were collected successfully within 5 days after receiving light stimulation and 5 days after stopping light stimulation during recovery. Based on the results, in the absence of other interfering factors, the patients received high-intensity light stimulation by using the system during the day, and the overall sleep duration increased at night, the proportion of deep sleep duration increased; the number of nocturnal awakenings, the number of body movements decreased significantly, and the sleep quality of the patients improved significantly. And the effect of light stimulation on sleep improvement was sustained after 5 days of discontinuation.

Currently, the system has been applied in 6 hospitals and 2 nursing institutions in China and served more than 20,000 cardiology catheter surgery, 200 severe cases of postoperative rehabilitation, 14,000 cases of orthopedics and brain emergency surgery,18,000 cases of maternal delivery, 370 cases of demented elderly living care and 500 cases of ophthalmic surgery and postoperative rehabilitation. The following feedback results in the clinical application of the therapeutic lighting system indicate that specific light environment can remarkably improve the patient emotion and rhythm, and that light environment design is the effective method to assist in patient rehabilitation and promote health benefits.

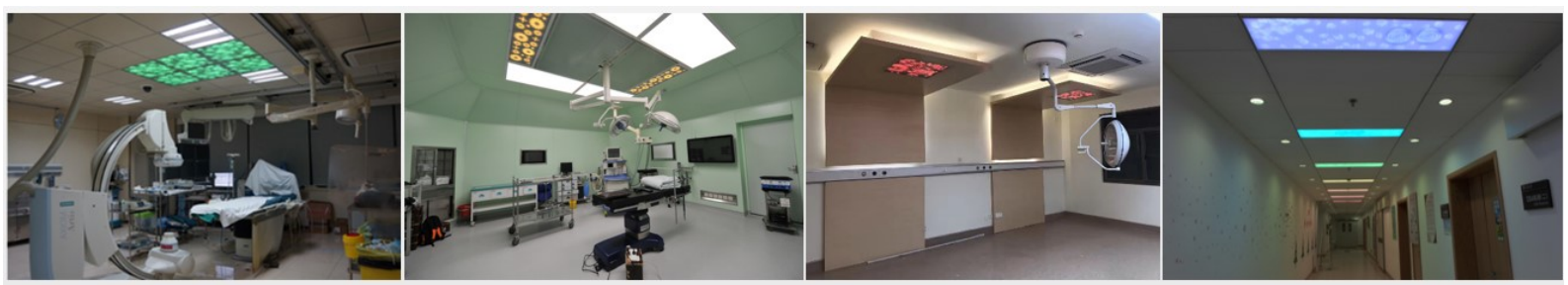

Figure 6 - Demonstration and application in various medical spaces

\section{Implications}

Under the guidance of "evidence-based" method, and according to the technical route of "demand research and related research - evidence-based design research - technology research and development and strategy - demonstration application and effect evaluation", the influence of lighting on circadian rhythm and emotional impact of Chinese patients is discussed. Moreover, the method of applying the research results of light health mechanism to the improvement of living environment is explored. With the lighting environment as active health intervention means, biological rhythm, and mood and pressure adjustment are achieved. The health lighting research and design strategies for Chinese patients with different types of disease are preliminarily established. Besides, it is proved that lighting is an effective method of helping patients recover and improving health and welfare, so it has a good prospect of application.

In order to ensure the objectivity and credibility of the results of evidence-based experimental research, the experimental method of "multi-method simultaneous measurement and mutual verification" combining subjectivity and objectivity are used, and virtual reality (VR) technology is also introduced for lighting scene display. However, the results of objective biochemical index analysis and physiological signal detection are often difficult to effectively reflect the changes of rhythm and emotional state at the data level or are affected by larger individual differences. For the problem, on the one hand, the sample size shall be enlarged and the experimental observation period shall be extended in the follow-up studies to obtain more effective and repeatable conclusions. On the other hand, the study on rhythm and emotion itself is highly complex, and involves many interfering factors, and it is difficult to avoid making mistakes which influence the conclusion in the process of the experiment. The experimental scene setting, experimental method flow and experimental instrument selection still remain to be optimized. Cross-disciplinary and multidisciplinary collaborative research involving medical and psychology teams is particularly critical in future healthy lighting research. 


\section{Funding}

National Key Research and Development Program of China (No. 2017YFB0403704).

\section{References}

Araújo Filho, G., Gomes, F., Mazetto, L., Marinho, M., Tavares, I., Caboclo, L., Yacubian, E. and Centeno, R. (2012). Pre-surgical mood disorders associated to worse post-surgical seizure outcome in patients with refractory temporal lobe epilepsy and mesial temporal sclerosis. Journal of Epilepsy and Clinical Neurophysiology, 18(1), pp.21-25. (Doi:10.1590/s1676-26492012000100006)

Pinto, A., Faiz, O., Davis, R., Almoudaris, A. and Vincent, C. (2016). Surgical complications and their impact on patients' psychosocial well-being: a systematic review and metaanalysis. BMJ Open, 6(2), p.e007224.

Ballesta A, Innominato PF, Dallmann R, Rand DA, Lévi FA. 2017. Systems Chronotherapeutics. Pharmacol Rev. 69(2):161-199. (Doi:10.1124/pr.116.013441)

Bedrosian, T. and Nelson, R. (2017). Timing of light exposure affects mood and brain circuits. Translational Psychiatry, 7(1), pp.e1017-e1017.(Doi:10.1038/tp.2016.262)

Cajochen, C., Münch, M., Kobialka, S., Kräuchi, K., Steiner, R., Oelhafen, P., Orgül, S., WirzJustice, A. 2005. High Sensitivity of Human Melatonin, Alertness, Thermoregulation, and Heart Rate to Short Wavelength Light. The Journal of Clinical Endocrinology \& Metabolis m, 90(3), pp.1311-1316.(Doi:10.1210/jc.2004-0957)

Duffy, J. and Czeisler, C. 2009 . Effect of Light on Human Circadian Physiology. Sleep Medicine Clinics, 4(2), pp.165-177.(Doi: 10.1016/j.jsmc.2009.01.004)

Figueiro, M., Kalsher, M., Plitnick, B., Rohan, C. and Rea, M. (2018). 0295 Tailored Lighting Intervention For Alzheimer's Patients And Its Effects On Sleep, Mood And Agitation. Sleep, 41(suppl_1), pp.A113-A114.(Doi:10.1093/sleep/zsy061.294)

Knez, I. and Kers, C. 2000. Effects of Indoor Lighting, Gender, and Age on Mood and Cognitive Performance. Environment \& Behavior, 32(6), pp.817-831 (Doi:10.1177/00139160021972810)

Kondratov, R. 2014. Circadian clock and cancer therapy: an unexpected journey. Annals of Medicine, 46(4), pp.189-190.(Doi:10.3109/07853890.2014.920213)

Küller, R., Ballal, S., Laike, T., Mikellides, B. and Tonello, G. 2006. The impact of light and colour on psychological mood: a cross-cultural study of indoor work environments. Ergonomics, 49(14), pp.1496-1507.(Doi:10.1080/00140130600858142)

Lavoie, M., Lam, R., Bouchard, G., Sasseville, A., Charron, M., Gagné, A., Tremblay, P., Filteau, M. and Hébert, M. 2009. Evidence of a Biological Effect of Light Therapy on the Retina of Patients with Seasonal Affective Disorder. Biological Psychiatry, 66(3), pp.253258.(Doi:10.1016/j.biopsych.2008.11.020)

McCormick King, M., Mee, L., Gutierrez-Colina, A., Eaton, C., Lee, J. and Blount, R. 2013. Emotional Functioning, Barriers, and Medication Adherence in Pediatric Transplant Recipients. Journal of Pediatric Psychology, 39(3), pp.283-293.(Doi: 10.1093/jpepsy/jst074)

Plitnick, B., Figueiro, M., Wood, B. and Rea, M. (2010). The effects of red and blue light on alertness and mood at night. Lighting Research \& Technology, 42(4), pp.449.(Doi:458.10.1177/1477153509360887)

Sajan, J., Cinu, T., Chacko, A., Litty, J. and Jaseeda, T. 2009. Chronotherapeutics and Chronotherapeutic Drug Delivery Systems. Tropical Journal of Pharmaceutical Research, 8(5): 467-475.(Doi:10.4314/tjpr.v8i5.48091) 